\title{
A Educação alimentar na escola municipal Professora Maria Villany Delmondes: um estudo sobre os corantes alimentícios
}

\author{
Food Education public school teacher Maria Villany Delmondes: a study on food colors
}

Tatiane Fernandes Campos¹, Luciany Fernandes Campos' ${ }^{1}$ Jorge Luiz da Silva², Arnaldo Gonçalves de Campos${ }^{2}$, Simone da Silva Santos ${ }^{1}$ e Daniela Raphanhin da Silva ${ }^{1}$

\author{
${ }^{1}$ Graduado, Núcleo Avançado de Jaciara, Instituto Federal de Educação, Ciência e Tecnologia de Mato Grosso - Campus \\ São Vicente, Jaciara, MT, Brasil \\ ${ }^{2}$ Mestre (professor), Núcleo Avançado de Jaciara, Instituto Federal de Educação, Ciência e Tecnologia de Mato Grosso -
} Campus São Vicente, Jaciara, MT, Brasil

\begin{abstract}
Resumo
O presente trabalho consiste em apresentar os resultados obtidos através de uma intervenção realizada na Escola Municipal Professora Maria Villany Delmondes. O trabalho teve como tema a educação alimentar no ensino fundamental, sendo realizado com 36 alunos do sexto e oitavo anos. O objetivo foi verificar o conhecimento dos alunos sobre os corantes alimentícios, bem como sensibilizá-los sobre hábitos alimentares mais saudáveis, buscando através de atividades práticas e lúdicas novas estratégias de ensino do tema abordado. Buscou-se o estudo dos corantes alimentícios em sala de aula interagindo e discutindo com os alunos. Para realização da intervenção utilizou-se de um questionário prévio para constatar o conhecimento dos alunos, no qual observou-se que a grande maioria (71\%) apresentaram conhecimento sobre os corantes alimentícios. Foram executados jogos durante a aula para que houvesse interação e assimilação do conteúdo, entre estes o jogo do paladar, o jogo da velha e o jogo das cartas perguntas, nos quais os alunos participaram significativamente, tirando as dúvidas. Além das atividades lúdicas, também realizou-se a prática de extração do corante natural de urucum. A pesquisa foi satisfatória no qual dos 36 alunos entrevistados, $78 \%$ acharam ótimas as atividades práticas e os jogos aplicados, e $97 \%$ dos alunos relataram que estas atividades os ajudaram a entender melhor o conteúdo. Constatou-se que os alunos aprovaram a metodologia aplicada, no qual se sentiram interessados em participar da aula e estimulados em desenvolver a reconstrução dos conceitos sobre os corantes alimentícios.
\end{abstract}

Palavras-chave: Aditivos Químicos. Ensino de Ciências. Experimentação. Ensino-aprendizagem.

\begin{abstract}
The present work is to present the results obtained through an intervention performed at the Municipal School Professora Maria Villany Delmondes. The work was the theme of nutrition education in elementary school, being conducted with 36 students of the sixth and eighth years. The objective was to evaluate the students' knowledge of food colors, as well as sensitize them about healthier eating habits, searching through practices and play activities new teaching strategies of the subject. We sought to study the food colors in the classroom interacting and discussing with students. For performing surgery we used a questionnaire prior to observe the students' knowledge, which showed that the vast majority $(71 \%)$ had knowledge of food colors. Plays were performed during class so that there was interaction and assimilation of content among these game taste, the pound and the set of questions letters, in which students participated significantly, taking questions. In addition to recreational activities, also held the practice of extraction of natural annatto dye. The research was satisfactory in which the 36 students interviewed, $78 \%$ felt great practical activities and applied games, and $97 \%$ of students reported that these activities helped them better understand the content. It was found that students approved the methodology applied, in which they felt interested in participating in class and encouraged to develop the reconstruction of concepts on food colors.
\end{abstract}

Keywords: Chemical Additives. Science Education. Experimentation. Teaching and learning. 


\section{Introdução}

Muitas escolas trabalham questões relacionadas à alimentação de forma superficial, por meio dos temas transversais contidos nos Parâmetros Curriculares Nacionais (PCN's, 1997), e conteúdos dos livros didáticos, levando a uma visão sucinta sobre alimentação e saúde.

O aluno precisa adquirir consciência da qualidade e segurança dos alimentos, além de compreender os malefícios provocados pelo consumo exagerado de produtos industrializados. Necessita-se de um estudo mais aprofundado sobre a utilização dos aditivos químicos na alimentação. Surge então a necessidade de entender as ações dos corantes alimentícios, sua constituição (naturais e artificiais), suas vantagens, desvantagens e legislação, devido ao seu grande uso na alimentação das pessoas.

Outro ponto a ser desenvolvido é a conciliação do conteúdo abordado com o cotidiano dos alunos, além do desenvolvimento de dinâmicas de ensino do conceito de corantes alimentícios em sala de aula, para isto aplicando ferramentas de aprendizado e assimilação dos conteúdos, por meio de atividades práticas e também de atividades lúdicas.

Neste sentido, buscou-se o estudo dos corantes, visto que a educação é um meio de formar cidadãos conscientes, e também devido à alimentação ser fundamental à vida humana.

Pinheiro e Abrantes (2011) realizaram um estudo, com 504 crianças entre 3 a 9 anos, sobre o consumo de alimentos industrializados, nas escolas particulares do bairro da Tijuca no município do Rio de Janeiro - RJ, no qual aproximadamente $88 \%$ das crianças consomem semanalmente guloseimas, tais como balas e chicletes, produtos esses com quantidade significativa de corantes na sua composição.

Esclarecer sobre o consumo desses aditivos e promover hábitos alimentares saudáveis se torna um grande desafio, principalmente com as crianças, as mais atraídas com as cores dos alimentos.

O papel do professor é assegurar um ambiente em que os alunos possam reconhecer e refletir suas ideias, tornar a aula mais agradável, fazendo com que as crianças se divirtam e ao mesmo tempo aprendam algo importante que está presente no seu cotidiano, que é a alimentação saudável, além de poder explorar as habilidades e competências que cada aluno apresenta.

Neste trabalho pretendeu-se sensibilizar os alunos do ensino básico referente à utilização de corantes em alimentos.

\section{Ensino de Ciências, educação alimentar e os alimentos}

O objetivo fundamental do ensino de Ciências Naturais, segundo os PCN's (1998), modificou-se dando condições ao aluno de vivenciar o que anteriormente se denominava método científico, por meio das observações, levantamento de hipóteses, ou trabalhando de forma a redescobrir os conhecimentos. Desta forma, evitando que muitas práticas ainda sejam pautadas, simplesmente, na transmissão de informações, tendo como únicos recursos o livro didático e a lousa, e levam muitos professores a perderem a oportunidade de trabalhar com maior amplitude e novas dinâmicas.

Assim, o ensino de Ciências se dá por um processo de desenvolvimento ativo, onde o estudante passa a ter condições de dominar o conteúdo e o método aplicado pelo professor, podendo participar das aulas de forma direta, com opiniões próprias, experiências vivenciadas no dia a dia, tornando o conhecimento mais amplo (BRASIL, 1998).

Nos dias atuais para manter um ensino de qualidade é preciso que o professor utilize várias técnicas de aprendizagem dentro da sala de aula, buscando informações em bibliografias diversificadas, relacionando o conteúdo com o cotidiano dos alunos, além de seguir uma metodologia de ensino nas aulas, tendo suporte nas atividades práticas e lúdicas.

Segundo Zapparoli (2012) existem muitas concepções sobre as atividades lúdicas na escola. Uma delas diz respeito a uma divisão entre o momento de aprender e o momento de brincar, promovendo desenvolvimento em várias áreas. Espinoza (2011) ressalta que as atividades lúdicas 
apresentam diversas vantagens no trabalho escolar, no sentido de contribuir para o desenvolvimento intelectual e físico, melhorando as habilidades de aprendizado do aluno.

Atualmente o professor se encontra em busca de soluções concretas para os problemas que surgem no contexto de ensino. Entre esses problemas está a falta de interesse dos alunos nos conteúdos estudados, desta maneira usar-se de práticas diferenciadas para ensinar torna-se uma forma auxiliar dentro do processo de ensino-aprendizado, onde sair do que é tradicional (modelo quadro e giz) dentro das escolas se torna um grande desafio aos educadores (ESPINOZA, 2011).

No que diz respeito às atividades práticas Andrade e Massabni (2011) afirmam que Estudo do meio, experimentação, visita com observações, entre outras, são exemplos do que se pode chamar de atividades práticas. Este é um momento crucial para fundamentar a construção de uma visão científica, com sua forma de entender e explicar as leis, fatos e fenômenos da natureza, bem como as implicações socioambientais deste conhecimento.

As atividades práticas vêm somar ao conhecimento que professor e alunos trazem para a aula, sendo possível ajudar os discentes a entenderem como funcionam os fenômenos cotidianos, por meio de práticas simples, utilizando-se materiais acessíveis e de baixo custo. O professor precisa organizar e coordenar o processo de aprendizagem, adaptando suas ações às características de cada aluno, para desenvolver suas capacidades e habilidades intelectuais (BRASIL, 1997).

Durante o estudo dos alimentos, se faz necessário que o professor trabalhe com os alunos os seus hábitos e costumes alimentares, ressaltando a importância dos nutrientes para a saúde e manutenção da vida.

A alimentação está intimamente ligada à saúde das pessoas, com toda a modernidade e tecnologia do século XXI, as pessoas têm adaptado a sua alimentação conforme o tempo, a praticidade e as condições econômicas disponíveis, na maioria das vezes optando por produtos industrializados com alto teor de gorduras, sódio e aditivos químicos.

A escola vem contribuir significativamente com orientação sobre hábitos alimentares mais saudáveis, promovendo a construção do conhecimento, contribuindo com a qualidade de vida dos alunos.

Conforme consta nos PCN's, a escola cumpre papel destacado na formação dos cidadãos para uma vida saudável, associando o grau de escolaridade ao nível de saúde dos indivíduos e grupos populacionais. A educação para o autocuidado, eleva a escola ao papel de protagonista, capazes de valorizar o bem-estar, discernir e participar de decisões relativas à saúde individual e coletiva. Portanto, a formação do aluno para o exercício da cidadania compreende a motivação e a capacitação, assim como a compreensão da saúde como direito e responsabilidade pessoal e social (BRASIL, 1997).

É importante ressaltar que a escola não trata seus alunos como pacientes, apenas os motivam a compreender que a alimentação é fundamental para manter suas atividades vitais além de melhorar o seu rendimento escolar (BRASIL, 2012).

Consta na Resolução, no 38, de 16 de julho de 2009 (no seu artigo 4.․), do Fundo Nacional de Desenvolvimento da Educação (FNDE), que o atendimento sobre a alimentação escolar aos alunos da educação básica no Programa Nacional de Alimentação Escolar (PNAE), tem como objetivo contribuir para o crescimento e o desenvolvimento biopsicossocial, a aprendizagem, o rendimento escolar e a formação de práticas alimentares saudáveis dos alunos, por meio de ações de educação alimentar e nutricional e da oferta de refeições que cubram as suas necessidades nutricionais durante o período letivo (BRASIL, 2009).

\section{Metodologia}

Este trabalho foi realizado na escola Municipal Maria Villany Delmondes, localizada no município de Jaciara-MT, durante os meses maio a novembro de 2014.

A pesquisa foi realizada com 41 alunos, sendo 23 do $6^{\circ}$ ano e 18 do $8^{\circ}$ ano, por meio de intervenção com duração de quatro aulas de 50 minutos cada. 
O projeto foi executado em etapas, onde a primeira etapa foi a aplicação de um questionário, como forma de sondagem, para saber o conhecimento prévio dos alunos sobre o assunto e quais as principais dificuldades apresentadas. As perguntas tiveram o objetivo de saber a opinião dos discentes sobre o conceito de corantes alimentícios, a classificação dos corantes, a identificação dos alimentos coloridos consumidos pelos alunos e sobre a leitura de rótulos de alimentos.

Em seguida realizou-se a segunda etapa, que constou das seguintes atividades.

\subsection{Exposição dos conceitos}

Após analisar o questionário prévio, iniciou-se o estudo com o auxílio de um texto, no qual os alunos participaram de uma leitura voluntária sobre a definição dos aditivos químicos, enfatizando os corantes, as suas classificações, órgãos que fiscalizam a quantidade permitida para cada alimento, os corantes que são permitidos no Brasil, além dos estudos sobre as doenças relacionadas ao consumo excessivo desses aditivos em produtos industrializados.

Após as discussões sobre o assunto com os alunos, em sala de aula e de sanadas as principais dúvidas sobre os corantes, abordaram-se então a questão dos corantes naturais, definindo, discutindo e aprofundando com o estudo do corante extraído da semente do urucum, planta conhecida dos alunos e que é muito utilizada na culinária.

\subsection{Execução do teste oral (feedback)}

Foram feitas diversas perguntas, de forma oral, verificando se os alunos compreenderam o conteúdo, além de auxiliar na fixação do mesmo. Entre elas perguntou-se o que são corantes, quais os tipos e como são classificados, qual o órgão responsável por fiscalizar a quantidade de corantes permitidas em cada alimento, além de exemplos sobre corantes naturais e artificiais.

\subsection{Dinâmica 1: Jogo da velha}

Dividiu-se a sala em dois grupos e cada grupo teve um líder responsável por responder as perguntas sobre os corantes alimentícios.

O tabuleiro do jogo da velha (feito com E.V.A. e com os campos numerados) foi fixada no quadro negro para facilitar o manuseio e desenvolvimento do jogo (Figura 1). Os líderes dos grupos escolhiam um número do tabuleiro, sendo que cada número correspondia a uma pergunta sobre o assunto, que foi respondida pelos membros da equipe.

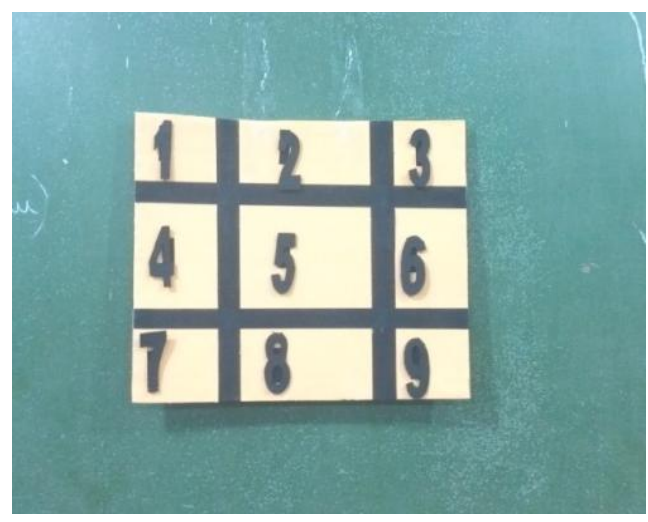

Figura 1 - Tabuleiro utilizado durante o jogo da velha

Conforme o grupo ia acertando os questionamentos, foram preenchendo a tabela com a lógica do jogo da velha (ganha o grupo conseguir formar sequências, tanto, na horizontal, vertical ou diagonal). A equipe vencedora foi a que obteve a maior pontuação através dos acertos, ou a que conseguiu preencher o jogo primeiro. 


\subsection{Dinâmica 2: Pesquisa nos rótulos das embalagens dos produtos}

Os alunos foram divididos em dois grupos. Foram entregues às equipes embalagens de produtos industrializados de diversos setores alimentícios, e os mesmos tiveram que identificar nos rótulos das embalagens os tipos de corantes e separá-los identificando os naturais e os artificiais (Figura 2). Após a identificação, um aluno representando o grupo foi à frente da sala para explicar aos demais colegas os tipos de corantes encontrados por cada equipe.
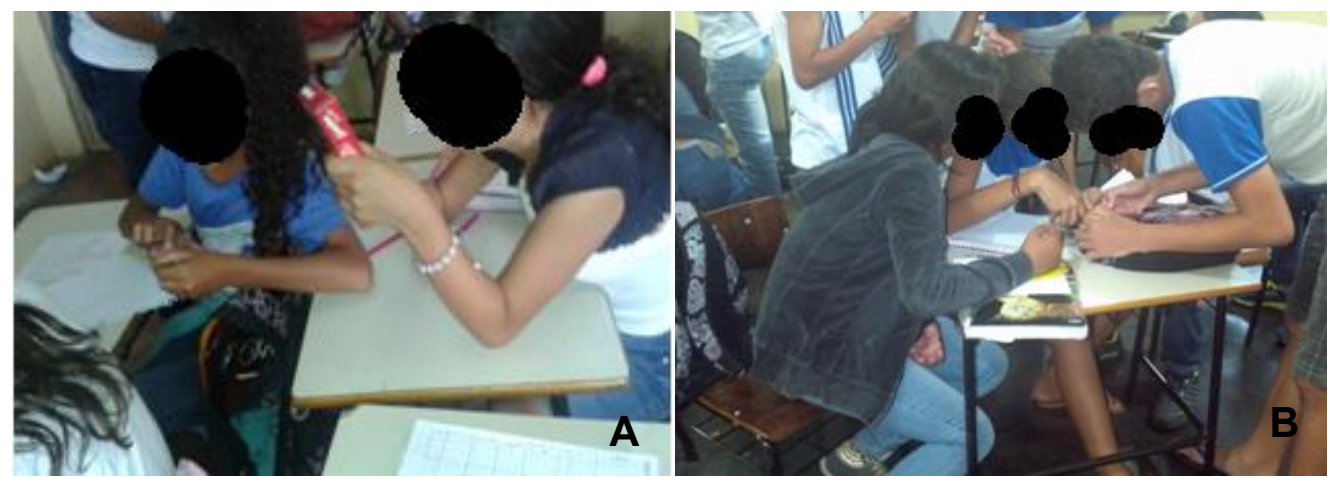

Figura 2 - A) Alunos do $6^{\circ}$ Ano pesquisando os tipos de corantes descritos nos rótulos das embalagens de produtos industrializados. B) Alunos do $8^{\mathrm{o}}$ ano pesquisando os tipos de corantes descrito nos rótulos das embalagens

\subsection{Dinâmica 3: Teste da degustação}

Foram expostas duas mesas, sendo uma contendo alimentos elaborados com corantes naturais (pão e refrigerante caseiro) e a outra contendo alimentos com corantes artificiais (pão e refrigerante industrializados, obtidos no comércio local) (Figura 3).
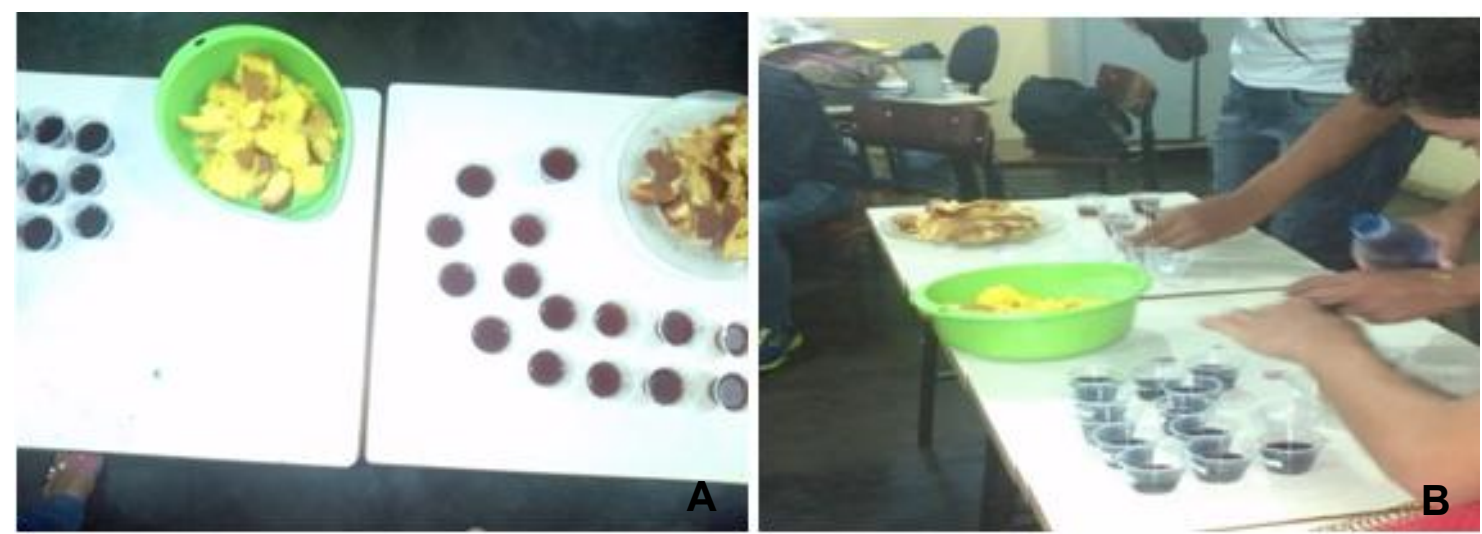

Figura 3 - A) Mesa expostas com produtos para a degustação. B) Exposição dos alimentos

Os alunos degustaram os alimentos e em seguida responderam um questionário, verificando se conseguiriam encontrar diferenças entre os produtos (elaborados com diferentes tipos de corantes) por meio de suas características sensoriais (cor, sabor, aroma e textura).

\subsection{Dinâmica 4: Extração do corante natural}

Primeiramente, distribui-se a semente de urucum (Bixa Orellana L.) já aquecida em óleo de soja (procedimento preparado anteriormente). Em seguida, iniciou-se o processo de extração, socando a semente com a farinha de milho (Fubá), utilizando um socador de alho. O processo foi gradativo, onde os alunos foram macerando as sementes e acrescentando o fubá aos poucos (Figura 4). 
Após conseguirem obter o produto de cor alaranjada, passou-se para o processo de peneiração, no qual os participantes da equipe separaram todo o corante adquirido e posteriormente armazenaram em saquinhos plásticos.
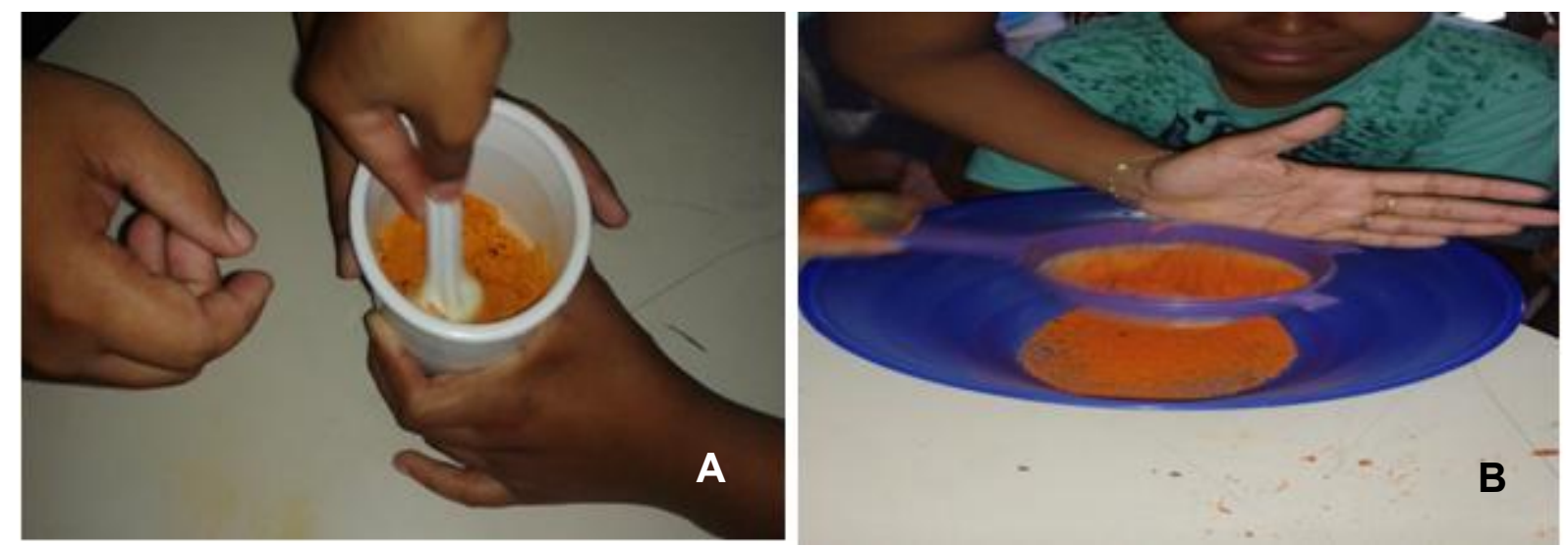

Figura 4 - A) Alunos macerando as sementes de urucum com farinha de milho. B) Processo de peneiração do corante extraído.

Os corantes produzidos foram sorteados ao final entre os membros das equipes participantes.

\subsection{Dinâmica 5: Jogo das cartas perguntas}

Este jogo consistiu de um baralho contendo 20 cartas, sendo 10 contendo perguntas e 10 contendo respostas, sobre o assunto.

Formou-se pares, onde um participante jogou uma carta contendo uma pergunta sobre o assunto já trabalhado e o outro respondeu jogando outra carta com a resposta correta. O jogo foi monitorado pelas acadêmicas regentes da intervenção para que ao final não tivessem erros no resultado.

\subsection{Questionário avaliativo}

Aplicou-se para os alunos, um questionário avaliativo, com a finalidade de que pudessem expressar os conhecimentos adquiridos, bem como demonstrar o que acharam da forma como o conteúdo foi abordado, referente aos conceitos, às atividades práticas, jogos realizados e sobre a compreensão das aulas. Repetiram-se algumas perguntas do questionário prévio para analisar se os alunos aprimoraram o que já conheciam.

Como devolutiva para a escola, foi entregue à coordenação uma apostila contendo todo o roteiro e os procedimentos para a execução da intervenção, os jogos pedagógicos confeccionados e também três mudas de urucuzeiro (planta que fornece o urucum), onde levou-se os alunos envolvidos neste trabalho para plantarem estas mudas em locais apropriados da escola.

\section{Resultado e discussão}

\subsection{Verificação dos conhecimentos prévios e apresentação de conceitos}

Constatou-se por meio deste questionário que os alunos sabem a definição do que são corantes alimentícios, como são classificados, porém apresentavam certa dificuldade em citar os tipos de corantes conhecidos. 
Entre os entrevistados, $71 \%$ responderam de forma correta que os corantes são substâncias responsáveis em transferir e exaltar as cores dos produtos. Os demais $12 \%$ disseram que são responsáveis por melhorar a textura dos produtos e 17\% em conferir aroma.

Estes resultados são vistos como satisfatórios, pois a grande maioria dos alunos apresentaram noções sobre o conceito de corantes, destacando, porém, que uma quantidade significativa (29\%) não o tem. Além de evidenciar que estes alunos têm dificuldade em relacionar os diferentes órgãos do sentido.

Em resposta a segunda pergunta, dentre os alimentos industrializados que contém corantes os mais citados foram: salgadinhos, bolachas, refrigerantes, chocolates, chicletes, balas, pirulitos, sucos em pó, iogurtes e salsichas. Assim pode-se analisar que estes tipos de alimentos estão presentes na alimentação diária dos alunos, e ressalta-se que muitos desses produtos apresentam grandes quantidades de corantes artificiais.

Quanto a citação de produtos naturais, destacaram-se as frutas como maçã, laranja, banana, uva, manga, tomate. Além dos vegetais, alface, couve, brócolis, rúcula, beterraba e dos grãos arroz e feijão, demonstrando que muitos alimentos naturais também fazem parte da alimentação dos alunos.

Quando questionados se conheciam algum tipo de corante alimentício, 58,5\% disseram que não conheciam e 41,5\% disseram conhecer, e os mais citados foram colorau, urucum e corante de bolo (anilina).

Perguntou-se ainda se tinham o costume de ler os rótulos das embalagens dos produtos que consomem, $58,5 \%$ disseram que não lêem e $41,5 \%$ disseram ter costume de ler os rótulos. Entre as respostas justificadas, destacaram-se:

"Para ler a validade";

"Para saber como faz o alimento";

"Para saber como foi feito";

"Porque precisamos saber quais os ingredientes têm, e se fazem bem";

"Tenho curiosidade de saber o que contém em o que como";

Estes dados são extremamente relevantes, pois deve-se estimular a curiosidade dos alunos, e uma destas formas é o ato de verificar as substâncias que compõem o seu alimento, além de compreenderem o que estão ingerindo, extrapolando as fronteiras da sala de aula, ou melhor, conciliando a teoria com a prática.

Um dos papéis da escola é subsidiar os alunos com os conhecimentos e as capacidades para tornarem aptos a discriminar informações, identificar valores agregados a essas informações e realizar escolhas (BRASIL, 1998).

Os alunos aprendem a partir do conhecimento que já possuem, desta forma o conhecimento prévio se torna importante para que o professor perceba como este se dá em seus alunos. Segundo Piaget (1990), o conhecimento se realiza através de construções contínuas e renovadas a partir da interação com o real, não ocorrendo através de mera cópia da realidade, e sim pela assimilação.

Para Martins, o professor deverá partir dos pressupostos que o importante é descobrir como os alunos gostam ou gostariam de aprender, e que: "ele não é o instrutor, nem transmissor de conhecimento, mas apenas mediador, pois os saberes são construídos pelos próprios alunos em suas mentes a partir da participação e interação que tiveram e das experiências vivenciadas por eles" (MARTINS, 2009, p. 41)

As discussões em sala de aula serviram para sanar as principais dúvidas sobre os corantes, pelo qual demonstraram bastante interesse e a aula se tornou bem participativa.

A todo o momento procurou-se estabelecer um diálogo participativo, com o intuito de instigar o conhecimento dos alunos, bem como auxiliá-los na construção do conhecimento.

Para tanto os PCN's (1997) afirmam que o professor poderá promover a desestabilização dos conhecimentos prévios, criando situações em que se estabeleçam os conflitos necessários para a aprendizagem. Desta forma acontece uma troca mútua de conhecimentos, enriquecendo a relação educador-educando. 
Desta maneira, Freire (2005, p. 79) “o educador já não é o que apenas educa, mas o que, enquanto educa é educado, em diálogo com o educando que ao ser educado também educa. Ambos, assim se tornam sujeitos do processo em que crescem juntos".

O professor consciente não pode esquecer que, em termos de aproveitamento o que interessa não é o conteúdo que se ensina, mas aquilo que os alunos aprendem e, sobretudo, como aprendem (MARTINS, 2009).

A importância do professor é o compromisso com a sociedade. Sua responsabilidade é preparar os alunos para se tornarem cidadãos ativos e participantes na família, no trabalho, nas associações de classe, na vida cultural e política (LIBÂNEO, 1994).

\subsection{Teste oral}

O teste oral foi executado por meio de perguntas espontâneas, onde os alunos puderam responder de forma satisfatória, demonstrando que compreenderam os conceitos apresentados. A grande maioria não apresentaram dificuldades para responder as questões, já alguns tiveram que consultar o texto utilizado em sala de aula para definirem as respostas.

Freire (2011) relata sobre o pensar certo afirmando que a tarefa coerente do educador que pensa certo é, exercendo como ser humano, a irrecusável prática de inteligir, desafiar o educando com quem se comunica, a quem comunica, a produzir sua compreensão do que vem sendo comunicado.

\subsection{Jogo da velha}

Com a utilização de um tabuleiro fixado no quadro com os números, os alunos puderam "brincar" e responder as questões, no qual houve grande interação e participação maciça. Nesta dinâmica apenas um grupo foi vencedor, mas todos tiveram a oportunidade de demonstrar $o$ conhecimento adquirido além de trabalhar a lógica do jogo, que era formar uma sequência precisa.

As atividades lúdicas apresentam diversas vantagens no trabalho escolar, no sentido de contribuir para o desenvolvimento intelectual e físico, melhorando as habilidades de aprendizado do aluno (ESPINOZA, 2011).

Para Balbinot (2005), o conhecimento científico pode estar relacionado com atividades que envolvam a emoção e a construção de modelos da realidade, de uma forma criativa.

Em sua pesquisa sobre uso de modelos, numa perspectiva lúdica, no ensino de Ciências, Balbinot constatou que o aluno percebe a facilidade em adquirir novos conhecimentos a partir da construção de modelos, os quais vão utilizar para ampliar seus modelos mentais, além de que, a vivência e o realismo dos objetos estudados tornam a aula mais prazerosa e motivadora (BALBINOT, 2005).

Santos (1997), aponta que a educação lúdica deve possibilitar ao futuro educador conhecer-se como pessoa, saber de suas resistências e ter uma visão clara sobre a importância da brincadeira para a vida da criança, do jovem e do adulto.

“Desta forma, o professor que conseguir promover a interação com seus alunos por meio da diversão poderá obter melhores resultados na aprendizagem, além de utilizar de recursos alternativos variados, envolvendo os alunos e comprometendo-os no próprio processo de aprendizagem" (MARTINS, 2009, p. 35).

\subsection{Pesquisa nos rótulos das embalagens dos produtos}

Utilizou-se da prática de investigação onde os alunos puderam procurar nos rótulos das embalagens dos alimentos, os tipos de corantes presentes. Todos os grupos participaram espontaneamente demonstrando estarem surpresos por descobrirem os mais variados tipos de corantes presentes na composição dos alimentos que estão consumindo em seu cotidiano. 
Para Freire (2011) o bom clima pedagógico-democrático é o em que o educando vai aprendendo, à custa de sua própria prática, que suas curiosidades, como suas liberdades, devam estar sujeitas a limites, mas em permanente exercício.

Por meio desta atividade os alunos puderam aprender através de um objeto, neste caso, os rótulos das embalagens.

Nos seres humanos o ato de aprender decorre da interação da pessoa com o objeto a ser conhecido, uma vez que é pela relação sujeito-objeto que ela incorpora novas representações mentais, compara-as com as que possui anteriormente, interpreta-as e constrói significados pela influência de fatores culturais e sociais, em outros termos, adquiri conhecimento (MARTINS, 2009).

“Outra finalidade das situações práticas de estudo é ensinar as crianças a observarem os detalhes, não só pela curiosidade, mas também pela investigação, pesquisando e descobrindo novos saberes ocultos nas diferenças" (MARTINS, 2009, p. 23).

\subsection{Teste da degustação}

Na turma do $6 .^{\circ}$ ano, $55 \%$ responderam que a bebida mais saborosa foi a que apresentava corante natural na sua formulação. Já para o $8 .^{\circ}$ ano, $74 \%$ dos alunos preferiram a bebida que continha corante artificial (Figura 5).

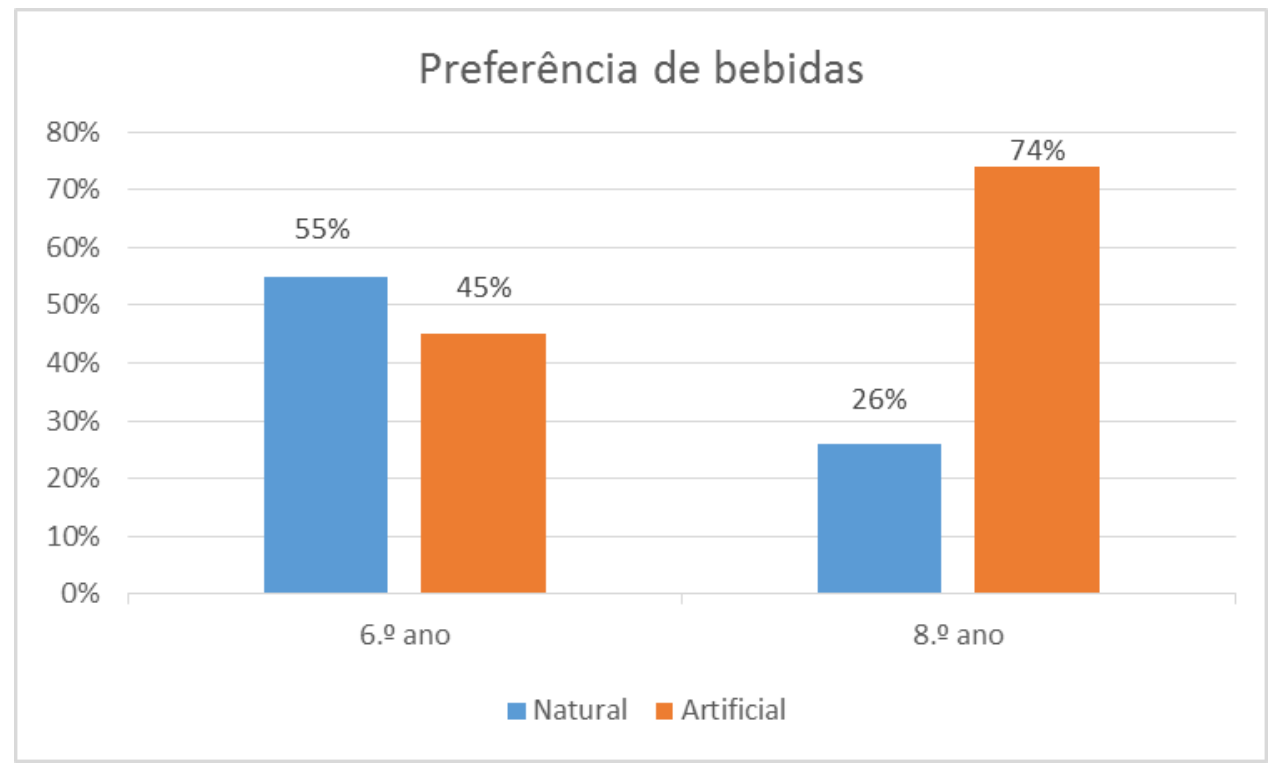

Figura 5 - Respostas dos alunos sobre o tipo de bebida mais saborosa.

Em relação a bebidas que mais chamaram atenção, $83 \%$ dos alunos optaram pela bebida que apresentava corante artificial. Demonstrando que as bebidas industrializadas, principalmente os refrigerantes chamam a atenção dos consumidores na hora da alimentação.

Com relação ao pão, $55 \%$ dos alunos do $6 .^{\circ}$ ano, preferiram o que continha corante natural. Já para o $8 . .9$ ano, $53 \%$ dos alunos acharam mais saboroso o pão que continha corante artificial.

Quando perguntados quais dos pães apresentados continha na formulação corante natural, a maioria dos alunos erraram ( $55 \%$ para o $6 .^{\circ}$ ano e $73 \%$ para o 8. ${ }^{\circ}$ ano). Já para as bebidas, houve maior

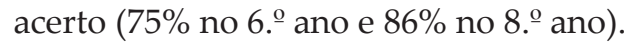

Em relação a quais alimentos chamaram mais atenção, $60 \%$ dos alunos do $6 .{ }^{\circ}$ ano optaram pelo pão com corante natural. Já no $8^{\circ}$ ano, $67 \%$ preferiram o alimento com corante artificial.

Por meio do teste da degustação, os alunos puderam além de perceber as diferenças existentes entre os alimentos, no tocante à utilização de corantes em sua elaboração, diferenciar por meio das características sensoriais (cor, sabor, aroma e textura), relatando as cores que chamaram mais atenção e o sabor mais atraente. 


\subsection{Extração do corante}

$\mathrm{Na}$ extração do corante da semente de urucum os alunos puderam conhecer o nome científico da planta, bem como métodos de extração e separação (peneiração), e como resultado obteve-se o colorau utilizado na culinária para fabricação de pães, molhos, margarinas entre outros.

Durante a extração discutiu-se sobre alguns conceitos científicos, como a questão de solubilidade, pois a substância bixina (presente na semente de urucum) ao ser aquecida, juntamente com o óleo vegetal, para liberação da coloração presente na semente, apresenta característica lipossolúvel. Neste momento os alunos trocaram experiências afirmando já ter visto na família a utilização do produto obtido, no caso o colorau ou colorífico.

Sobre o conhecimento prévio que os alunos já possuem, Freire (2011) diz que é dever do professor, bem como da escola, de não só respeitar os saberes com que os educandos, sobretudo os das classes populares, chegam a ela. Desta forma, o professor como ser mediador, deve levar os alunos a reconstruir estes conhecimentos já possuídos, focando-os num pensamento mais voltado ao científico.

Para Giordan (1999, p. 2) "a elaboração do conhecimento científico depende de uma abordagem experimental, fundamentalmente porque a organização desse conhecimento ocorre preferencialmente nos entremeios da investigação". Tomar a experimentação como parte de um processo pleno de investigação é uma necessidade, reconhecida entre aqueles que pensam e fazem o ensino de Ciências, pois a formação do pensamento e das atitudes do sujeito deve-se dar preferencialmente nos entremeios de atividades investigativas (GIORDAN, 1999).

Rosito (2008, p. 197) diz que "no ensino de Ciências, as atividades experimentais não devem ser desvinculadas das aulas teóricas, das discussões em grupo e de outras formas de aprenderem". Levar assim, a prática de extração do corante como forma de experimentação aos alunos, proporcionou momentos de interação e aprendizagem em sala de aula.

\subsection{Jogo das cartas perguntas}

Como forma de interação os alunos participaram efetivamente no jogo das cartas desenvolvido para que eles pudessem brincar e ao mesmo tempo exercitar o que aprenderam durante a aula. Houve grande interação entre as duplas que se ajudaram mutuamente e, com o auxílio das professoras mediadoras puderam sanar as dúvidas que iam aparecendo ao longo do jogo.

Em virtude disso, Martins (2009) relata que a aprendizagem deverá ser processada de maneira que envolva integralmente o aluno, quanto aos aspectos cognitivos, racional, emocional, lógico, imaginário, intuitivo. Sendo assim, o professor pode aproveitar das vantagens que as práticas da aprendizagem podem lhe oferecer.

A utilização de jogos potencializa, por meio das atividades desenvolvidas, "a exploração e a construção do conhecimento, por contar com a motivação interna típica do lúdico" (KISHIMOTO, 1996, p.37).

\subsection{Questionário avaliativo}

No questionário avaliativo os alunos puderam expressar os conhecimentos adquiridos, bem como relatar o que acharam da forma como o conteúdo foi abordado.

Quando questionados sobre o conceito de corantes, a maioria (83\%) responderam corretamente, dizendo que os corantes são substâncias responsáveis por transferir ou exaltar as cores dos alimentos.

Ainda para verificar o conhecimento, perguntou-se aos alunos quais os tipos de corantes que aprenderam, e $89 \%$ responderam corretamente.

Perguntou-se ainda porque os alunos achavam que alguns alimentos eram bem coloridos, e $83 \%$ dos entrevistados disseram que era para chamar a atenção, $11 \%$ responderam que eram para serem mais saborosos e $6 \%$ responderam que era para diferenciar os sabores. 
Constatado o grau de aprendizado dos alunos, comparando o que tinham de conhecimento antes da intervenção e após o assunto ter sido trabalhado, e dos esclarecimentos das dúvidas, foi analisada a parte do questionário voltado para a maneira como assunto foi abordado.

Para isso perguntou-se aos alunos se haviam gostado da forma como o conteúdo foi abordado, e $95 \%$ responderam que sim, que gostaram, e a minoria (5\%) responderam negativamente.

Acredita-se que estes 5\% (correspondente a 2 alunos) que responderam não ter gostado da forma como o conteúdo foi abordado, são alunos que demonstraram não estarem com a atenção voltada para a questão da aprendizagem, como relata Freire (2005, p. 79) "ninguém educa ninguém, ninguém educa a si mesmo, os homens se educam entre si mediatizados pelo mundo".

Entende-se então, que para aprender é preciso ter a atenção voltada para tal e que esta pode ser desviada por vários motivos, não se esquecendo que a "força motriz da aprendizagem é o interesse por aquilo que se quer aprender" (MARTINS, 2009, p. 45).

Perguntou-se ainda, o que acharam das atividades práticas e dos jogos aplicados durante a aula, e a maioria total, $78 \%$, responderam que foram ótimas, já $14 \%$, responderam que foram boas, enquanto $5 \%$ disseram serem regulares e $3 \%$ responderam que as atividades foram ruins.

Pelo fato de alguns alunos apresentarem dificuldades no momento de aprendizagem dos conteúdos, neste caso na área específica do ensino de Ciências, perguntou-se aos alunos se as atividades aplicadas ajudaram a entender melhor o conteúdo, e a maioria, 97\%, responderam que sim e somente $3 \%$ disseram que não.

E para analisar se os mesmos gostaram da aula, perguntou-se o que eles mais gostaram e entre as respostas estão:

"Jogos e extrair corantes";

"Modo de explicar o conteúdo";

"Da degustação";

"As atividades práticas e das explicações";

"Das explicações, tipo de tudo";

"As brincadeiras";

"Experimentar os alimentos diferentes";

A aplicação do questionário avaliativo norteou a pesquisa no sentido de avaliar se o aprendizado foi relevante aos alunos. Sobre a avaliação, Leal (2014) ressalta que é uma etapa presente que exerce uma função fundamental, que é a função diagnóstica. Por meio desta prática, o professor pode perceber as dificuldades do aluno e desta forma, tentar ajudá-lo a superá-las.

Para Martins (2009) o professor deverá levar em conta o sentido exato de avaliar como meio formativo pela qual é dada ênfase ao aprender realizado pelo aluno, não como julgamento, nem classificação, mas como busca de meios para melhor o conhecimento sobre o tema.

\section{Conclusão}

A aplicação desta intervenção permitiu verificar que os alunos apresentam conhecimentos prévio sobre os corantes alimentícios e, que também conseguiram relacionar o conteúdo com o seu cotidiano. Estes conhecimentos possibilitaram que os alunos participassem da aula, aumentando a capacidade de refletir e questionar sobre como tem sido os seus hábitos alimentares, e o que poderiam mudar daqui em diante.

Através das atividades práticas e lúdicas, os estudantes conseguiram relacionar os conhecimentos já existentes com o conhecimento científico, favorecendo a reorganização de suas ideias, além de sentirem interessados e motivados por estarem integrados no processo de ensinoaprendizagem.

A metodologia aplicada possibilitou sensibilizar os alunos em relação aos corantes presentes nas composições dos alimentos, alertando para os possíveis riscos à saúde, devido ao consumo 
exagerado destes compostos na alimentação, que tem sido cada vez mais baseada em produtos industrializados.

Todas as práticas trabalhadas foram consideradas atrativas, motivadoras e apresentaram interferências positivas no aprendizado dos alunos. Através das respostas do questionário avaliativo constatou-se que eles aprovaram a metodologia aplicada, no qual se sentiram interessados em participar da aula e estimulados em desenvolver a reconstrução dos conceitos sobre os corantes alimentícios.

\section{Agradecimentos}

Ao IFMT - Campus São Vicente, pelo apoio no projeto e à escola estadual Santo Antônio por ter liberado o acesso aos seus estudantes; e à Coordenação de Aperfeiçoamento de Pessoal de Nível Superior (CAPES) pelo subsídio através do Programa de Consolidação das Licenciaturas (PRODOCENCIA) Edital 019/2013, processo № 113.657, e do Programa Institucional de Bolsa de Iniciação à Docência (PIBID) Edital № 061/2013, processo № 128.570, IFMT/Campus São Vicente/Sub Projeto Ciências.

\section{Referências}

ANDRADE, M. L. F.; MASSABNI, V. G. O Desenvolvimento de Atividades Práticas na Escola: Um Desafio Para os Professores de Ciências. Ciências e Educação, Bauru-SP, v. 17, n. 4, p. 835-854, 2011.

BALBINOT, M. C. Uso de Modelos, Numa Perspectiva Lúdica, no Ensino de Ciências. IN: IV Encontro Ibero-Americano de Coletivos Escolares e Redes de Professores que Fazem Investigação na sua Escola, 2005.

BRASIL. Manual de Orientação Para a Alimentação Escolar na Educação Infantil, Ensino Fundamental, Ensino Médio e na Educação de Jovens e Adultos/ [organizadores Francisco de Assis Guedes de Vasconcelos... et al. _ 2 ed. _ Brasília: PNAE: CECANE - SC, 2012, 48 p.

BRASIL. Ministério da Educação. Fundo Nacional do Desenvolvimento - Conselho Deliberativo. Resolução/CD/FNDE $n^{\circ}$ 38, de 16 de julho de 2009. Dispõe sobre o atendimento da alimentação escolar aos alunos da educação básica no Programa Nacional de Alimentação Escolar - PNAE. Diário Oficial da República Federativa do Brasil. Brasília - DF. Disponível em: http://www.fnde.gov.br/arquivos/category/60-2012?download=57:res038-16072009. Acesso: 01/09/2014.

BRASIL. Secretaria de Educação Fundamental. Parâmetros Curriculares Nacionais: Ciências Naturais/ Secretaria de Educação Fundamental. Brasília: MEC/SEF, 1998, 138 p.

BRASIL. Secretaria de Educação Fundamental. Parâmetros Curriculares Nacionais: Apresentação dos Temas Transversais, Ética/ Secretaria de Educação Fundamental. Brasília: MEC/SEF, 1997, 146 p.

ESPINOZA, A. Ciências na Escola: Novas Perspectivas Para a Formação dos Alunos. São Paulo, Ed. Ática, 2011.

FREIRE, P. Pedagogia da Autonomia: saberes necessários á pratica educativa/ Paulo Freire, São Paulo, Paz e Terra, 2011.

FREIRE, P. Pedagogia do Oprimido. Rio de Janeiro, Paz e Terra, 2005. 
GIORDAN, M. O Papel da Experimentação no Ensino de Ciências. IN: II Encontro Nacional de Pesquisa em Educação em Ciências, 1999.

KISHIMOTO, T. M. Jogo, brinquedo, brincadeira e a educação. Cortez, São Paulo, 1996.

LEAL. R. B. Planejamento de Ensino Peculiaridades Significativas. Revista Ibero-Americana de Educação, 2014. Disponível em: www.rieoei.org/indecphp. Acesso em 01 de Fevereiro de 2015.

LIBÂNEO, J.C. Didática. Ed. 1. São Paulo: Editora Cortez, 1994.

MARTINS, J. S. Situações Práticas de Ensino e Aprendizagem Significativa. São Paulo: Autores Associados, 2009.

PIAGET, J. Epistemologia Genética. São Paulo: Martins Fontes, 1990.

PINHEIRO, M. C. O.; ABRANTES, S. M. P. Avaliação da Exposição aos Corantes Artificiais Presentes em Balas e Chicletes por Crianças entre 3 e 9 anos Estudantes de Escolas Particulares da Tijuca/ Rio de Janeiro. Revista Analyttica. Editora Eskalab, 2011.

ROSITO, B. A. O Ensino de Ciências e a Experimentação. In: MORAES, R. Construtivismo e ensino de Ciências. 3. ed. Porto Alegre: EDIPUCRS, 2008. 230 p.

SANTOS, S. M. P. (Org). O Lúdico na Formação do Educador. Petrópolis: Vozes, 1997.

ZAPPAROLI, K. Estratégias Lúdicas da Criança com Deficiência/ Kelem Zapparoli_ Rio de Janeiro: Wak Editora, 2012. 